\title{
Clinical Report \\ Tetra-Amelia and Lung Hypo/Aplasia Syndrome: New Case Report and Review
}

\author{
Sérgio B. Sousa, ${ }^{1 *}$ Raquel Pina, ${ }^{2}$ Lina Ramos, ${ }^{1}$ Naigel Pereira, ${ }^{3}$ Martin Krahn, ${ }^{4}$ Wiktor Borozdin, ${ }^{5}$ \\ Jürgen Kohlhase, ${ }^{5}$ Marta Amorim, ${ }^{1}$ Katia Gonnet, ${ }^{4}$ Nicolas Lévy, ${ }^{4}$ Isabel M. Carreira, ${ }^{6}$ \\ Ana Bela Couceiro, ${ }^{3}$ and Jorge M. Saraiva ${ }^{1}$ \\ ${ }^{1}$ Serviço de Genética Médica, Centro Hospitalar de Coimbra, Coimbra, Portugal \\ ${ }^{2}$ Serviço de Anatomia Patológica, Centro Hospitalar Coimbra, Coimbra, Portugal \\ ${ }^{3}$ Centro de Diagnóstico Pré-Natal da Maternidade Bissaya Barreto, Coimbra, Portugal \\ ${ }^{4}$ Laboratoire de Génétique Moléculaire, Département de Génétique Médicale, Hôpital d'enfants La Timone, Marseille, France \\ ${ }^{5}$ Center for Human Genetics, Freiburg, Germany \\ ${ }^{6}$ Laboratório Citogenética, Instituto Biologia Médica, Faculdade de Medicina da Universidade de Coimbra, Coimbra, Portugal
}

Received 9 February 2008; Accepted 18 June 2008

Tetra-amelia is a rare malformation that may be associated with other anomalies and is usually inherited in an autosomal recessive pattern. We describe a fetus, born to a nonconsanguineous couple, with tetra-amelia, bilateral cleft lip and palate and bilateral lung agenesis, without other anomalies. Karyotype was normal $(46, \mathrm{XX})$ and premature centromere separation was excluded. No mutation was identified upon molecular analysis of WNT3, HS6ST1, and HS6ST3. We reviewed the literature and the differential diagnosis to clarify the clinical delineation of conditions associated with tetra-amelia. The present report describes the sixth family with this pattern of malformations and reinforces the evidence that the "tetra-amelia and lung hypo/ aplasia syndrome" is a distinct autosomal recessive condition, with no identified gene thus far. (c) 2008 Wiley-Liss, Inc.

Key words: tetra-amelia; lung aplasia; cleft lip/palate

How to cite this article: Sousa SB, Pina R, Ramos L, Pereira N, Krahn M, Borozdin W, Kohlhase J, Amorim M, Gonnet K, Lévy N, Carreira IM, Couceiro AB, Saraiva JM. 2008. Tetra-amelia and lung hypo/aplasia syndrome: New case report and review. Am J Med Genet Part A 146A:2799-2803.

\section{INTRODUCTION}

Congenital limb defects have a birth prevalence of 0.55 per 1,000 [Evans et al., 1994]. Amelia, the complete absence of one limb, has a birth prevalence of 0.01 per 1,000 births, in which $50 \%$ are syndromic [Evans et al., 1994]. Tetra-amelia, the complete absence of all four limbs, is even rarer, frequently inherited in an autosomal recessive pattern. It is usually described as part of a multiple congenital anomaly syndrome (MIM 273395, 301090 and 273390), associated with craniofacial, pulmonary, central nervous system, heart, skeletal, urogenital malformations, ectodermal dysplasia, and lacrimal duct anomalies. The clinical delineation of the different entities associated with tetra-amelia is complex and the molecular findings are limited.

We report an additional patient with tetra-amelia and lung hypo/aplasia syndrome and review the differential diagnosis and clinical delineation of the conditions associated with tetra-amelia.

\section{CLINICAL REPORT}

A 17-year-old healthy woman presented at 20 weeks of gestation in her first pregnancy. There was no known teratogen exposure. The father was a healthy 22-year-old man and there was no consanguinity or relevant family history.

The ultrasonographic evaluation at 20 weeks identified tetra-amelia, bilateral cleft lip and palate, and possible pulmonary hypoplasia. No other anomalies were detected and the amniotic fluid quantity was normal. Pregnancy was terminated at 22 weeks. Clinical examination of the fetus was consistent with the prenatal findings (Fig. 1) and, in addition, micrognathia and low-set ears were

*Correspondence to: Dr. Sérgio B. Sousa, M.D., Serviço de Genética Médica, Hospital Pediátrico de Coimbra, Av. Bissaya Barreto, 3000-076 Coimbra, Portugal. E-mail: sbsousa@hpc.chc.min-saude.pt

Published online 3 October 2008 in Wiley InterScience (www.interscience.wiley.com)

DOI 10.1002/ajmg.a.32489 

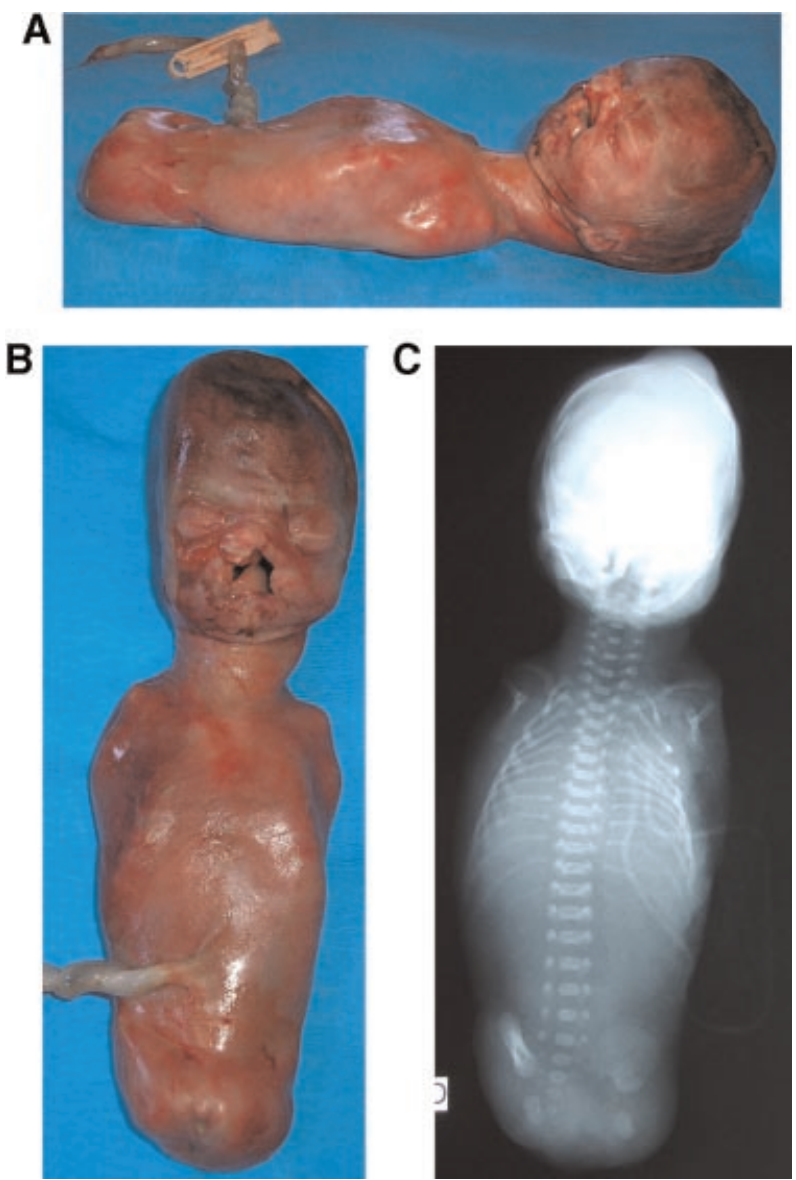

FIG. 1. A,B: Fetal phenotype: complete absence of the four limbs (tetraamelia) and facial cleft; (C) Fetal X-ray image showing a small thorax and the complete absence of limb bones with normal clavicles, scapulae and pelvis. [Color figure can be viewed in the online issue, which is available at www.interscience.wiley.com.]

observed. The pathological examination further revealed bilateral lung agenesis (Fig. 2), with bilateral pulmonary artery agenesis and a small right heart, and excluded genito-urinary anomalies. The fetal $\mathrm{X}$-ray confirmed the complete absence of limb bones and revealed normal clavicles, scapulae and pelvis (Fig. 1). Cytogenetic analysis of amniocytes and fetal

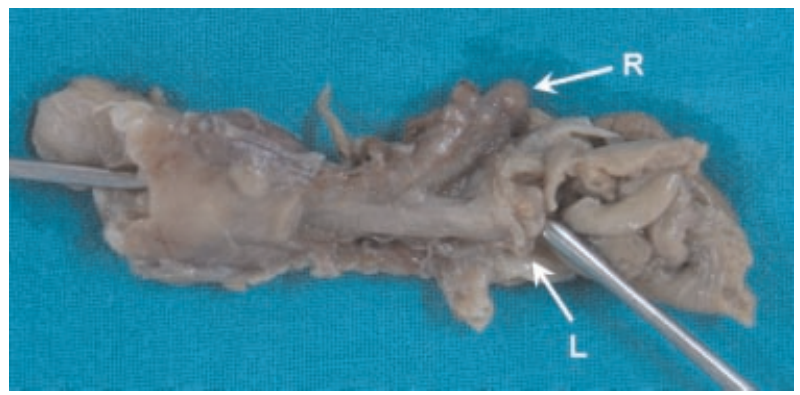

FIG. 2. Photograph of the posterior aspect of the tracheo-bronchial tree (esophagus sectioned) highlighting the bilateral lung agenesis with the right $(\mathrm{R})$ and left (L) blind-ended main bronchi. [Color figure can be viewed in the online issue, which is available at www.interscience.wiley.com.] blood was normal $(46, \mathrm{XX})$, and premature centromere division was excluded.

Genomic DNA was extracted from cultured amniocytes. WNT3 molecular analysis, being the only gene so far associated with tetra-amelia cases [Niemann et al., 2004], was performed by direct sequencing of the WNT3 coding region. No mutations were identified. Subsequently, following a candidate gene approach based on the involvement of the heparan sulfatase HS6ST in both limb bud development and tracheal branching evidenced in different animal models [Kamimura et al., 2001; Izvolsky et al., 2003; Nogami et al., 2004], coding regions of the HS6ST1 and HS6ST3 genes were screened for mutations using direct sequencing as previously described [Krahn et al., 2005]. No sequence variation was found in HS6ST1 gene. A homozygous SNP (rs9516771) was identified in exon 2 of the HS6ST3 gene, which was predicted to be non-pathogenic using bioinformatics PolyPhen SNPanalysis [Ramensky et al., 2002].

\section{DISCUSSION}

The clinical delineation of the different entities associated with tetra-amelia is not yet clear. The present report supports the specific pattern of malformations (tetra-amelia, lung hypo/aplasia and, inconsistently, cleft lip/palate) of the five previously reported families (14 affected fetuses/ infants) [Rosenak et al., 1991; Zlotogora et al., 1993; Basaran et al., 1994; Krahn et al., 2005] which are compared with the present patient and other conditions in the differential diagnosis in Table I. This condition, tetra-amelia and lung hypo/aplasia syndrome, has been classified as MIM273395.

The specific association of tetra-amelia, lung hypo/ aplasia and cleft lip/palate, was first reported by Rosenak et al. [1991] (OMIM 273395) in two fetuses from an apparently nonconsanguineous Arab Muslim couple, including an 18-week female with tetra-amelia, bilateral lung agenesis, left bronchoesophageal fistula, low-set ears and micrognathia and an 14-week male with tetra-amelia, left cleft lip and severe lung hypoplasia. This couple also had one amelic female offspring that died soon after birth (not examined) and four normal children. Cytogenetic analysis was only performed on the last affected fetus. It was normal $(46, \mathrm{XY})$ and no premature centromere separation was observed.

Later, Zlotogora et al., [1993] reported the incidence of tetra-amelia in two Muslim Palestinian Arab families. These families appeared to be unrelated but had the same geographical origin as the one described by Rosenak et al. [1991]. The first family described by Zlotogora et al., [1993] was a consanguineous couple that had seven children, two of which were affected females with enlarged head and tetra-phocomelia. In the second family, there were 
American Journal of Medical Genetics Part A

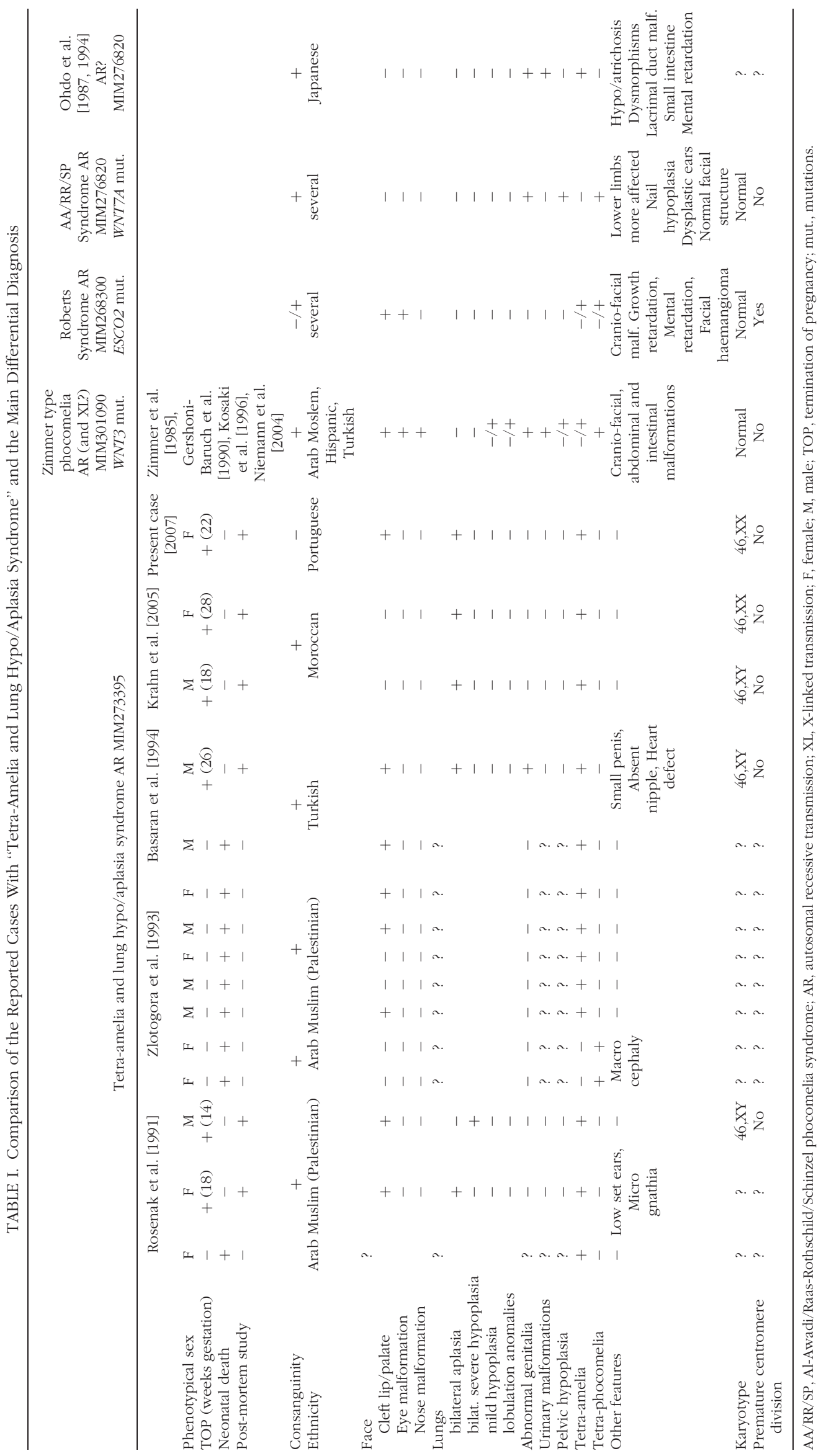


two consanguineous couples. The first one had 11 children, three of whom had tetra-amelia and one of those also had cleft lip. The second couple had two children with tetra-amelia and cleft lip. No cytogenetic analysis or autopsies were performed in these cases. All affected neonates from both families died soon after birth, which suggests that other malformations were present, namely pulmonary hypo/ aplasia.

Basaran et al. [1994] described two patients with tetra-amelia from a Turkish consanguineous couple that had one healthy daughter. The first patient was a term male infant who died soon after birth with tetraamelia and cleft lip-palate (no autopsy was performed). The second patient was a 26-week-old male fetus with tetra-amelia, bilateral complete cleft lippalate, bilateral palpebral fusion, micrognathia, absence of nipples, small penis, intra-abdominal testes, lung agenesis, ventricular septal defect, and mitral valve aplasia. Chromosomes were normal $(46, \mathrm{XY})$ without premature centromere division.

Krahn et al. [2005] reported two fetuses born to a consanguineous Morrocan couple who presented with tetra-amelia and bilateral pulmonary aplasia without other anomalies, also with normal cytogenetic studies. In that report, the existence of an abnormal FGFR2 isoform and mutations in WNT3, FGF10, HS6ST1, and HS6ST3 genes were excluded.

Niemann et al. [2004] reported the only family thus far with tetra-amelia and positive molecular findings. A consanguineous couple had four affected fetuses with tetra-amelia and cleft lip/palate, microphthalmia, nose malformation, choanal atresia, gastroschisis, diaphragmatic hernia, lung lobulation abnormalities, renal agenesis, spleen agenesis, malformed uterus, persistence of cloaca, urethral atresia, anal atresia, and single umbilical artery but without pulmonary hypo/aplasia. Homozygosity mapping followed by mutation analysis revealed a pathogenic homozygous mutation in the WNT3 gene. Although the clinical description of this family is also included under OMIM 273395, in our opinion and as previously suggested by Krahn et al. [2005], it fits better with the Zimmer type phocomelia phenotype (OMIM 301090).

Zimmer type phocomelia, initially described as Xlinked [Zimmer et al., 1985; Gershoni-Baruch et al., 1990; Kosaki et al., 1996], was further characterized by Kosaki et al. [1996] who reported a 46, XX fetus and suggested autosomal recessive inheritance. In the original family described by Zimmer there is no clear X-linked pattern of transmission. Genital anomalies precluded phenotypic sex determination in the fetuses and cytogenetic and pathological studies were only done in one of the seven affected fetuses. Features of this condition mainly include: tetraphoco/amelia, facial clefts, nose and eye malformations, kidney agenesis, imperforate anus and vagina and abnormal genitalia. The main features that distinguish Zimmer type phocomelia from tetraamelia and lung hypo/aplasia syndrome are the absence of severe pulmonary hypoplasia or aplasia and the presence of internal, genital and craniofacial (in addition to cleft lip/palate) anomalies in Zimmer type phocomelia. Taking into account the family reported by Niemann et al. and the arguments listed above, we conclude that mutations in WNT3 inherited in a recessive pattern are a cause of Zimmer type phocomelia. At present, there is not enough evidence to exclude the involvement of other genes and even an X-linked form, and further studies of other cases are required.

Several other authors have described cases with tetra-phoco/amelia as part of different patterns of malformation (Table I). One of the conditions in the differential diagnosis is Roberts syndrome-SC phocomelia (OMIM 268300), a well known disorder inherited in an autosomal recessive pattern characterized by a wide spectrum of limb deficiencies, severe craniofacial abnormalities, pre- and post-natal growth retardation, mental retardation and facial vascular malformations. It is associated with premature centromere separation and with homozygous mutations in ESCO2 gene [McDaniel et al., 2005; Vega et al., 2005].

The Al-Awadi/Raas-Rothschild/Schinzel phocomelia (AA/RR/SP) syndrome ("absence of ulna and fibula with severe limb deficiency", OMIM 276820) is characterized by limb defects, more severe in the lower limbs, pelvic hypoplasia, nail hypo/aplasia, and variable genitalia abnormalities. It is differentiated from the previous entities by the absence of pulmonary hypo/aplasia, absence of urinary and gastrointestinal malformations, normal facial structure and the presence of pelvic hypoplasia. Homozygous loss-of-function mutations in the WNT7A gene were identified in this condition, which is allelic to Fuhrmann syndrome ("fibular aplasia or hypoplasia, femoral bowing and poly-, syn- and oligodactyly", OMIM 228930) associated with partial loss of WNT7A function [Woods et al., 2006]. There is still uncertainty in the understanding of this family of syndromes (OMIM 276820 and OMIM 228930), namely concerning the inclusion of the Schinzel phocomelia (SP) phenotype [Lonardo et al., 2007].

Another recognized entity which has been described in one family [Ohdo et al., 1987, 1994] is "tetra-amelia with ectodermal dysplasia and lacrimal duct abnormalities" (OMIM 273390) which has autosomal recessive inheritance. There is mental retardation in addition to the features mentioned in its description.

In conclusion, we propose that the family reported by Niemann et al. [2004] should be considered as part of the Zimmer type phocomelia spectrum (OMIM 301090); the Zimmer type phocomelia should be more accurately considered as being inherited in an autosomal recessive pattern, with the possibility of 
genetic heterogeneity and a X-linked form, and the tetra-amelia and lung hypo/aplasia syndrome should be classified as a separate condition, as suggested [Kosaki et al., 1996; Krahn et al., 2005], associated with autosomal recessive transmission and with no identified gene. This hypothesis was supported by the exclusion of disease-causing mutations in WNT3 gene, and also in candidate genes, including HS6ST1 and HS6ST3, in the present and in the Krahn et al. [2005] cases. The modes of inheritance and MIM classification numbers of each condition are presented in Table I in accordance with these suggestions.

Additional molecular investigations are needed to further clarify the understanding of these rare conditions. Besides looking for new implicated genes, a more widespread study of the known genes (WNT3, namely in families with Zimmer type phocomelia, and $W N T 7 A$, especially in families with Shinzel phocomelia syndrome) would be useful.

\section{ACKNOWLEDGMENTS}

We acknowledge Prof. Nicole Philip (Département de Génétique Médicale, Laboratoire de Génétique Moléculaire, Département de Génétique Médicale, Hôpital d'enfants La Timone, Marseille, France) for her input on the study of this case.

\section{REFERENCES}

Basaran S, Yuksel A, Ermis H, Kuseyri F, Agan M, Yuksel-Apak M. 1994. Tetra-amelia, lung hypo-/aplasia, cleft lip-palate, and heart defect: A new syndrome? Am J Med Genet 51:77-80.

Evans JA, Vitez M, Czeizel A. 1994. Congenital abnormalities associated with limb deficiency defects: A population study based on cases from the Hungarian Congenital Malformation Registry (1975-1984). Am J Med Genet 49:52-66.

Gershoni-Baruch R, Drugan A, Bronshtein M, Zimmer EZ. 1990. Roberts syndrome or "X-linked amelia"? Am J Med Genet 37:569-572.

Izvolsky KI, Shoykhet D, Yang Y, Yu Q, Nugent MA, Cardoso WV. 2003. Heparan sulfate-FGF10 interactions during lung morphogenesis. Dev Biol 258:185-200.

Kamimura K, Fujise M, Villa F, Izumi S, Habuchi H, Kimata K, Nakato H. 2001. Drosophila heparan sulfate 6-O-sulfotransferase (dHS6ST) gene. Structure, expression, and function in the formation of the tracheal system. J Biol Chem 276:1701417021.
Kosaki K, Jones MC, Stayboldt C. 1996. Zimmer phocomelia: Delineation by principal coordinate analysis. Am J Med Genet 66:55-59.

Krahn M, Julia S, Sigaudy S, Liprandi A, Bernard R, Gonnet K, Heuertz S, Bonaventure J, Chau C, Fredouille C, Levy N, Philip N. 2005. Tetra-amelia and lung aplasia syndrome: Report of a new family and exclusion of candidate genes. Clin Genet 68:558-560.

Lonardo F, Sabba G, Luquetti DV, Monica MD, Scarano G. 2007. Al-Awadi/Raas-Rothschild syndrome: Two new cases and review. Am J Med Genet Part A 143A:3169-3174.

McDaniel LD, Tomkins DJ, Stanbridge EJ, Somerville MJ, Friedberg EC, Schultz RA. 2005. Mapping of a single locus capable of complementing the defective heterochromatin phenotype of Roberts syndrome cells. Am J Hum Genet 77:132-139.

Niemann S, Zhao C, Pascu F, Stahl U, Aulepp U, Niswander L, Weber JL, Muller U. 2004. Homozygous WNT3 mutation causes tetra-amelia in a large consanguineous family. Am J Hum Genet 74:558-563.

Nogami K, Suzuki H, Habuchi H, Ishiguro N, Iwata H, Kimata K. 2004. Distinctive expression patterns of heparan sulfate Osulfotransferases and regional differences in heparan sulfate structure in chick limb buds. J Biol Chem 279:8219-8229.

Ohdo S, Madokoro H, Sonoda T, Takei M, Yasuda H, Mori N. 1987. Association of tetra-amelia, ectodermal dysplasia, hypoplastic lacrimal ducts and sacs opening towards the exterior, peculiar face, and developmental retardation. J Med Genet 24:609-612.

Ohdo S, Sonoda T, Ohba K. 1994. Natural history and postmortem anatomy of a patient with tetra-amelia, ectodermal dysplasia, peculiar face, and developmental retardation (MIM 273390). J Med Genet 31:980-981.

Ramensky V, Bork P, Sunyaev S. 2002. Human non-synonymous SNPs: Server and survey. Nucleic Acids Res 30:3894-3900.

Rosenak D, Ariel I, Arnon J, Diamant YZ, Ben Chetrit A, Nadjari M, Zilberman R, Yaffe H, Cohen T, Ornoy A. 1991. Recurrent tetraamelia and pulmonary hypoplasia with multiple malformations in sibs. Am J Med Genet 38:25-28.

Vega H, Waisfisz Q, Gordillo M, Sakai N, Yanagihara I, Yamada M, van Gosliga D, Kayserili H, Xu C, Ozono K, Jabs EW, Inui K, Joenje H. 2005. Roberts syndrome is caused by mutations in ESCO2, a human homolog of yeast ECO1 that is essential for the establishment of sister chromatid cohesion. Nat Genet 37:468-470

Woods CG, Stricker S, Seemann P, Stern R, Cox J, Sherridan E, Roberts E, Springell K, Scott S, Karbani G, Sharif SM, Toomes C, Bond J, Kumar D, Al-Gazali L, Mundlos S. 2006. Mutations in WNT7A cause a range of limb malformations, including Fuhrmann syndrome and Al-Awadi/Raas-Rothschild/Schinzel phocomelia syndrome. Am J Hum Genet 79:402-408.

Zimmer EZ, Taub E, Sova Y, Divon MY, Pery M, Peretz BA. 1985. Tetra-amelia with multiple malformations in six male fetuses of one kindred. Eur J Pediatr 144:412-414.

Zlotogora J, Sagi M, Shabany YO, Jarallah RY. 1993. Syndrome of tetraamelia with pulmonary hypoplasia. Am J Med Genet 47:570-571. 